\title{
Unresolved Issues and Future Perspectives
}

\author{
Marco Merlo, Giulia De Angelis, Antonio Cannatà, \\ Laura Massa, and Gianfranco Sinagra
}

\section{Abbreviations and Acronyms}

$\begin{array}{ll}\text { ARVC } & \text { Arrhythmogenic right ventricular cardiomyopathy } \\ \text { CMR } & \text { Cardiac magnetic resonance } \\ \text { DCM } & \text { Dilated cardiomyopathy } \\ \text { DMD } & \text { Dystrophin } \\ \text { ECG } & \text { Electrocardiogram } \\ \text { FLNC } & \text { Filamin C } \\ \text { HCM } & \text { Hypertrophic cardiomyopathy } \\ \text { ICD } & \text { Implantable cardioverter-defibrillator } \\ \text { LAEF } & \text { Left atrial emptying fraction } \\ \text { LGE } & \text { Late gadolinium enhancement } \\ \text { LMNA } & \text { Lamin A/C } \\ \text { LVEF } & \text { Left ventricular ejection fraction } \\ \text { NYHA } & \text { New York Heart Association } \\ \text { OMT } & \text { Optimal medical therapy } \\ \text { PLN } & \text { Phospholamban } \\ \text { RBM20 } & \text { RNA-binding motif protein } 20 \\ \text { RCM } & \text { Restrictive cardiomyopathy } \\ \text { RNA } & \text { Ribonucleic acid } \\ \text { SCD } & \text { Sudden cardiac death } \\ \text { TNNT2 } & \text { Troponin T2 } \\ \text { TTN } & \text { Titin }\end{array}$

M. Merlo $(\bowtie) \cdot$ G. Sinagra

Cardiovascular Department, Azienda Sanitaria Universitaria Integrata, Trieste, Italy e-mail: gianfranco.sinagra@asuits.sanita.fvg.it

G. De Angelis · A. Cannatà · L. Massa

Cardiovascular Department, Azienda Sanitaria Universitaria Integrata, University of Trieste (ASUITS), Trieste, Italy

e-mail: laura.massa@ asuits.sanita.fvg.it

(C) The Author(s) 2019

G. Sinagra et al. (eds.), Dilated Cardiomyopathy,

https://doi.org/10.1007/978-3-030-13864-6_14 


\subsection{Toward a Personalized Medicine: A Genetic Approach}

One of the major challenges in nonischemic Dilated Cardiomyopathy (DCM) is the complex and heterogeneous etiology of the disease [1].

Indeed, DCM is the final common pathway of different pathogenic processes, and distinguishing between this complex etiological diversity is emerging as a useful tool to a better prognostic stratification and a targeted therapy.

It has already been shown that post-myocarditis DCM could have a better prognosis compared to the idiopathic form [2]. Moreover, it is well known that secondary forms show reversibility after removing the trigger factors [3-5]. More undefined is the prognostic relevance of certain gene mutations in the setting of genetically determined DCM.

Over the years, there has been increasing evidence that DCM is a familial or genetic disease in a consistent proportion of cases. In this setting, the mere morphofunctional classification doesn't allow proper risk stratification, and the important information on the causal gene gets lost as well as the cascade familial genetic screening.

The relatively recent proposal of a new classification that integrates phenotype description and genetic information at the same level moves in this direction [6]. At the same time when genetic testing is becoming part of a routine, its role in decisionmaking is still very limited.

The cascade genetic familial screening remains the most direct consequence of a positive genetic test, in order to obtain an early diagnosis in relatives, as this facilitates prompt prophylactic therapy in early or preclinical disease with a subsequent improved clinical outcome [7].

Relatives without the mutation can be discharged, although the complex interaction between environmental factors and predisposing gene variants and the possible coexistence of multiple mutations in developing the dilated phenotype make it impossible to exclude at all a pathogenic evolution, even in the absence of the causal pathogenic mutation. On the contrary, mutation carriers deserve more frequent clinical surveillance. Given the incomplete penetrance of such mutations, the early identification of pathogenic predictors represents an intriguing issue to be deeper investigated.

In the past years, left ventricular enlargement in the absence of systolic dysfunction emerged as a possible predictor of progression to overt DCM in asymptomatic relatives [8].

More recently, modern imaging techniques, such as speckle tracking echocardiography, are getting ahead in the hazy area of preclinical diagnosis [9]. Interesting data on their capacity to identify subtle abnormalities in contractile function need to be improved with larger numbers and should be extended to cardiac magnetic resonance (CMR) feature tracking analysis.

A flash-forward to the future of personalized medicine could be the understanding of a precise genotype-phenotype correlation. Actually, many efforts of the clinical research are moving in this direction. The implications in terms of early diagnosis, prognostic stratification, and targeted therapy would be revolutionary. 
Lamin A/C (LMNA) mutations represent the example on how the identification of a specific mutation can change the routine management, by gaining a class IIa indication for ICD implantation in the presence of certain additional risk factors, regardless of left ventricular dysfunction severity [10].

The same gene is targeted by a new molecule, ARRY-797, which showed promising results in a phase II clinical trial. The small molecule is an inhibitor of the p38-MAPK pathway, which appears to be upregulated in $L M N A$-deficient mouse.

Other attempts to identify a genotype-phenotype correlation have been made riding the wave of $L M N A$, leading to interesting results.

For example, rare sarcomeric gene variants could harbor a poor long-term prognosis [11], while cytoskeleton Z-disk mutations demonstrate a lower rate of left ventricular reverse remodeling after optimized medical therapy [12].

Filling the gap of knowledge in this area requires many other efforts. The interpretation of the results of genetic testing is often hard, given the high prevalence of private mutations. To generate a response, it's necessary to assess the possible pathogenicity, based on structure-function models and evidence of interspecies conservation [13].

The pathogenic role of several mutations is still not well characterized. For example, some titin $(T T N)$ missense variants could have a potential pathogenic role, suggested by their nonrandom distribution in affected members [14].

Moreover, little is known about the role of modifier genes and environmental interaction on the development of an overt phenotype. A recent study highlighted a shared genetic predisposition in women with peripartum cardiomyopathy compared with patients with idiopathic dilated cardiomyopathy, suggesting that different insults could unmask the same dilative phenotype in patients with similar genetic background [15]. It is also probable that a genetic predisposition favors the development of a dilative phenotype in the presence of different trigger factors, such as inflammation, toxic insults from alcohol [16] or drugs, and tachycardia. Furthermore, the association of two or more potentially pathogenic factors has been associated with worse prognosis [17].

The complexity of mutational status in DCM is made more difficult by the absence of co-segregation of modifier genes. Variance component analysis may help to identify the relative impact of genetic and environmental factors. This technique allows a comparison of phenotypic variability within and between families carrying the same primary mutation [18].

Adding complexity to this context, the majority of genes responsible for DCM are not specific, but show a significant overlap with hypertrophic (HCM), restrictive (RCM), arrhythmogenic right ventricular cardiomyopathy (ARVC), and channelopathies [19]. Moreover, the distinctive phenotype of DCM (left ventricular dilation and dysfunction) can frequently overlap with other distinctive traits of different cardiomyopathies (Fig. 14.1). It is intriguing how the same mutation in the gene coding for troponin T (TNNT2) has shown variable phenotypic expression ranging from DCM to HCM and RCM within the same family [20]. Many genes are associated with arrhythmic tendency and are reviewed in the next paragraph. 


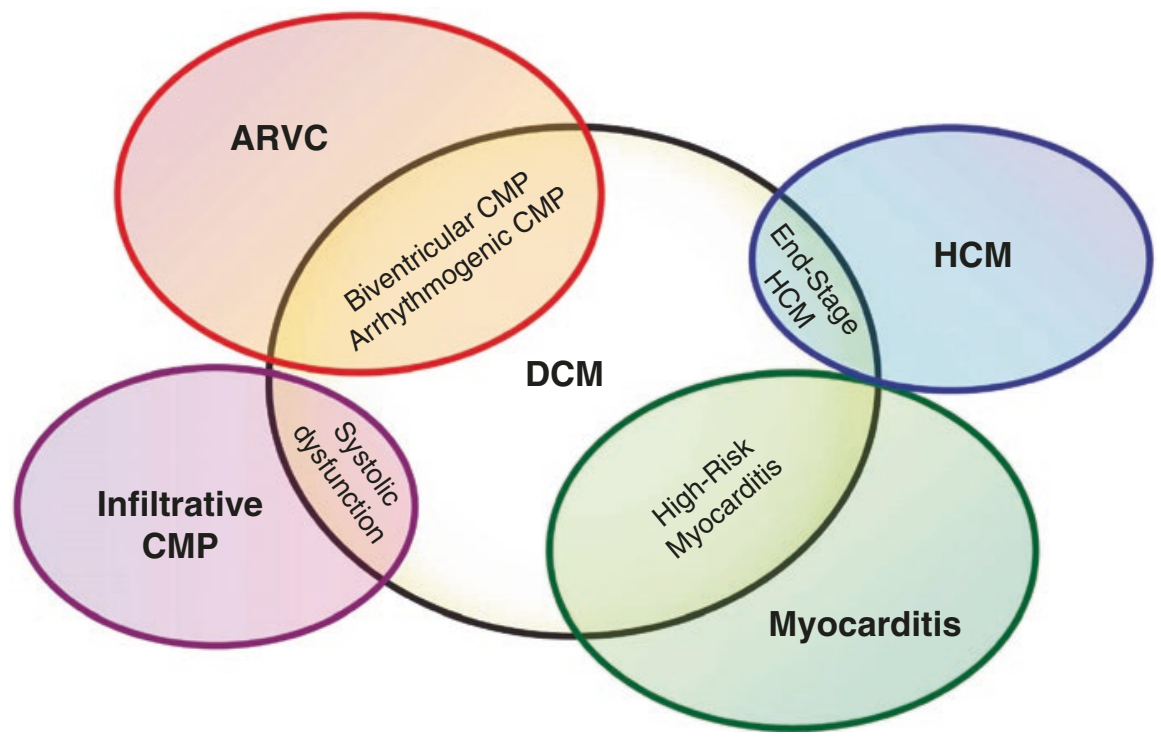

Fig. 14.1 Overlap phenotypes between DCM and other cardiomyopathies. ARVC arrhythmogenic right ventricular cardiomyopathy, $C M P$ cardiomyopathy, $D C M$ dilated cardiomyopathy, $H C M$ hypertrophic cardiomyopathy

Summing up, genetics currently represents one of the most important fields of increasing knowledge in order to further improve the outcomes of DCM. Early diagnosis, the complexity of genotype-phenotype interaction, the pathogenic role of certain mutations, and the interplay with environmental factors all represent unresolved issues to be better understood for improving care.

\subsection{The Challenge of Arrhythmic Stratification}

To date, another important open issue is the arrhythmic stratification, in order to carefully identify patients who are most likely to die from arrhythmia and could benefit from an implantable cardioverter-defibrillator (ICD), mostly in the first phases after diagnosis.

Mortality in DCM results typically from pump failure or sudden cardiac death (SCD). The latter occurs out of hospital in the majority of patients and could be prevented by an appropriate ICD intervention [21].

ICD implantation for primary prevention is recommended in patients with DCM, New York Heart Association (NYHA) classes II-III, and a left ventricular ejection fraction $(\mathrm{LVEF}) \leq 35 \%$ despite optimized medical therapy [22].

The capacity of this device to interrupt malignant arrhythmias, thus preventing death, is unquestionable. However, its role in preventing overall mortality in nonischemic DCM is still debated, given the negative results of many trials in the past years [23-25] and only one demonstrating benefit in both ischemic and nonischemic populations [26]. 
The recent publication of the DANISH trial has once again raised this issue [27]. While overall mortality was similar in both study groups, younger patients had a clear benefit from ICD implantation, resulting in reduction of overall mortality, other than SCD. The lower prevalence of comorbidities and competing causes of death in this population could explain this outcome.

This result would encourage the development of a new decisional algorithm for ICD implantation, in order to guarantee greater quality-adjusted life years and prevent futile inappropriate shocks and complications, such as device infections (respectively, $4.9 \%$ and $5.9 \%$ over 5.6 years in DANISH trial). It is well demonstrated in fact the negative prognostic impact of inappropriate ICD implantation [28].

The novel approach should at first make a negative selection, excluding patients with high mortality risk from competing causes. Several models have been developed to predict non-sudden mortality, based on clinical parameters [29] and serum biomarkers [30], claiming for a multiparametric algorithm that possibly combines clinical data, biomarker quantification, CMR evaluation, and genetic testing to predict the risk of death from pump failure rather than from malignant arrhythmia.

Once this negative selection has been made, patients at higher risk for SCD should be identified. By now, the only validated parameter is LVEF, being its relationship with the extent of myocardial lesion, and thus the arrhythmogenic risk, the physiopathological rationale.

Nonetheless, as discussed above, the selection of patients with nonischemic DCM based on this parameter has shown poor specificity and low incidence of appropriate therapies.

Useful information comes from a basic clinical approach. Easily collectable data, such as unexplained syncope, Holter ECG monitoring showing rapid nonsustained ventricular tachycardia, and frequent premature ventricular contraction and couplets, have been related to a higher incidence of SCD and malignant arrhythmias, even in the absence of overt heart failure. When combined with a family history of major arrhythmias or SCD, the risk was increased [31].

Integrating clinical data with the aforementioned genetic testing could increase the capacity to identify at-risk patients. Beyond the widely known LMNA mutations, other mutations have been related to arrhythmic phenotypes. Future-focused research should be developed, but some preliminary results are already available.

Truncating filamin C (FLNC) mutations have been associated with an overlapping phenotype of dilated and left-dominant arrhythmogenic cardiomyopathies, complicated by frequent premature SCD [32]. The same arrhythmic tendency has been shown in carriers of TNNT2 [33], phospholamban (PLN) [34], RNA-binding motif protein 20 (RBM20) [35], TTN [36], and desmosomal mutations. Together, these data suggest that, in the future, genotypes other than LMNA could benefit from an early ICD implantation independently from LVEF reduction.

Conversely, dystrophin (DMD) mutations have been related to a DCM phenotype more susceptible to heart failure than arrhythmic events. This mutation could identify patients whose treatment could be directed toward advanced heart failure therapies rather than protection from SCD.

A helpful prognostic tool could come from imaging techniques. Global longitudinal strain (GLS), assessed by means of echocardiography, could be a useful tool 
to evaluate arrhythmic risk in DCM patients, by identifying those with mechanical dispersion, which show higher arrhythmic propensity [37]. More recently, CMR strain imaging was shown to predict outcome in a nonischemic DCM population independently from validated parameters such as NYHA class and LVEF, but more studies are needed to clarify its role also in the setting of SCD.

Actually, CMR represents the most promising tool in assessing arrhythmic risk. The presence of late gadolinium enhancement (LGE), a marker of fibrosis, has been shown in approximately $30 \%$ of DCM patients [38]. Its presence and, less certainly, its extent have been related to a higher risk of SCD and aborted SCD, identifying a subgroup of patients at high risk of arrhythmic events independently from LVEF [39].

LGE is now widely assessed during follow-up of DCM patients, although its use as a marker of arrhythmogenicity has not yet been mentioned in clinical guidelines. But its robust correlation with SCD makes it the most suitable tool to be incorporated into combined models of prediction.

Less clear is the possible association between interstitial fibrosis, assessed by T1-mapping, and SCD. An association between T1 values and overall mortality has been shown, as well as with major arrhythmic endpoints [40].

Right ventricular systolic dysfunction at diagnosis and during follow-up appears as a powerful and independent predictor of mortality outcome in large series, although its role in favoring SCD itself is still not clarified [41, 42].

Finally, recent reports identified left atrial emptying fraction (LAEF), assessed by CMR, as an independent predictor of appropriate device therapy in patients with ischemic and dilated cardiomyopathy, who had an ICD in primary prevention [43].

Parameters of electrical instability, such as T-wave alternans or fragmented QRS at ECG, could improve models of prediction, but yet no single index of electrical instability was more accurate than LVEF in predicting arrhythmic events, although some showed high negative predictive value [44].

The same importance as the selection of patients is the correct timing of ICD implantation.

Only one third of patients with DCM, satisfying criteria for ICD implantation, maintain their eligibility after 3-9 months of OMT (optimal medical therapy) [45], making it mandatory a waiting period of at least 3 months of OMT. This period is very important, because inappropriate ICD implantation has not only an economic impact on public healthcare system but is also associated with higher in-hospital death and post-procedural complication rate [28].

Importantly, a non-negligible proportion of patients could die in the first 6 months, during therapy titration. These patients should be carefully identified, because they could benefit from an early ICD implantation or from a wearable cardioverter-defibrillator. Higher left ventricular end-systolic indexed volumes, longer QRS, and intolerance to beta-blockers have been shown to characterize this high-risk population [46], but further studies are needed to integrate these parameters into a validated, universally accepted multiparametric model. The role of wearable cardioverter-defibrillators in this setting is still debated, and registry studies failed to demonstrate a clear benefit of this bridge solution in nonischemic DCM [47]. Properly selected higher-risk patients should be evaluated into a randomized controlled trial, in order to obtain more robust data. 
Periodic reassessment of arrhythmic risk should also be performed, as DCM is a dynamic condition, with the possibility of exacerbation also after many years of stability. Moreover, the predictors of arrhythmogenicity may change at subsequent evaluations. Surprisingly, impaired LVEF was associated with worse arrhythmic outcome only in the long term, while best early predictors were, respectively, QRS duration, mitral regurgitation, and disease duration at baseline and NYHA functional class III or IV, syncope, disease duration, and left ventricular end-diastolic volume at 12-month evaluation [48].

In conclusion, the current guidelines show poor capacity to identify nonischemic DCM patients likely to benefit from primary prevention ICD implantation.

The way forward needs the identification of parameters, which should be incorporated together into a multiparametric and dynamic model, which permit an early identification of higher-risk patients and a periodic risk reassessment.

To pursue this objective, different approaches should be combined, ranging from clinical data, genetics, standard and modern imaging techniques, to electrophysiological data.

\subsection{Toward Innovation in Therapy}

Mortality rates in patients with DCM have significantly decreased over years. The basis of this success lies in the sequential introduction of drugs and the appropriate use of device therapy, which contributed to the decline of both cardiovascular and SCD risk [49].

The major leap came with the use of angiotensin-converting enzyme inhibitors, promptly followed by beta-blockers and mineralocorticoid-receptor antagonists. Despite the efficacy of these therapies, the spectrum of drugs used in heart failure due to DCM still remains very limited.

The recent introduction of the angiotensin receptor-neprilysin inhibitor sacubitril/valsartan raises the possibility for a further improvement of prognosis in DCM [50].

Nevertheless, all the currently approved drugs act on the common physiopathological mechanisms of heart failure. A big improvement would come from the development of therapies more specifically focused on DCM itself and its underlying mechanisms.

In this setting, the stimulation of the endogenous regenerative capacity of the myocardium and its replacement by new cells or tissue are promising paths to be further investigated.

The myocardium has poor intrinsic regenerative capacity, although resident cardiac progenitor cells have been shown to persist in adult mammalian hearts.

Given the role of paracrine signaling pathways in myocardial repair, a promising approach comes from the development of exosomes, whose effect has been investigated in several preclinical studies, targeted by now to the regeneration after myocardial infarction [51].

A similar mechanism of action is shared by autologous and allogenic mesenchymal stem cells derived from bone marrow and myocardial biopsies. 
The capacity of these cells to promote angiogenesis, mitigate inflammation and apoptotic cell death, and reduce myocardial fibrosis represents a good opportunity for their use in DCM.

In this sense, the demonstration of feasibility and safety of their transendocardial injection in 37 patients with nonischemic DCM is encouraging and should promote future research [52]. A caveat remains the risk of sensitization against donor cellspecific HLA that could hamper a future heart transplantation.

Likewise, in animal studies, gene therapy showed potential beneficial effects in the setting of nonischemic heart failure [53].

Last but not least, the small RNA-based therapeutics, hanging on the evidence of a pivotal role of microRNAs in the postnatal cardiomyocyte proliferation in animal models, represents a potential targeted therapy for myocardial regeneration [54].

Hence there are still many open issues to be deeper investigated by translational research in the way of understanding the mechanisms and developing targeted therapies in the field of DCM.

In conclusion, the very next future of DCM management should go through the better understanding of the etiology of the disease, the correct risk stratification, and the development of new therapies (Table 14.1). The rapidly increasing knowledge should be combined into an interconnected network with the purpose of a multiparametric evaluation of the disease.

Table 14.1 Unresolved issues and future perspectives in arrhythmic stratification of idiopathic dilated cardiomyopathy

\begin{tabular}{|c|c|c|}
\hline \multicolumn{3}{|c|}{ Unresolved issues and future perspectives in arrhythmic risk stratification } \\
\hline Critical issue & What is known & Future directions \\
\hline $\begin{array}{l}\text { Proper risk } \\
\text { stratification }\end{array}$ & $\begin{array}{l}\text { Primary prevention ICD: } \\
\text { Is recommended in NYHA class } \\
\text { II-III DCM patients with } \\
\text { LVEF } \leq 35 \% \text { despite OMT, with } \\
\text { survival expectancy }>1 \text { year } \\
\text { Should be considered in DCM } \\
\text { patients with LMNA mutation } \\
\text { and clinical risk factors (NSVT } \\
\text { during ambulatory ECG } \\
\text { monitoring, LVEF < 45\% at first } \\
\text { evaluation, male sex, non- } \\
\text { missense mutations) }\end{array}$ & $\begin{array}{l}\text { Creation of a multiparametric score, } \\
\text { which encompasses: } \\
\text { Clinical data (syncope; NSVT; family } \\
\text { history) } \\
\text { Search for proarrhythmic mutations } \\
\text { (LMNA; FLNC, etc.) } \\
\text { Functional imaging parameters (GLS; } \\
\text { LAEF) } \\
\text { Structural imaging parameters (LGE; } \\
\text { T1 mapping) } \\
\text { Parameters of electrical instability } \\
\text { (T-wave alternans, fragmented QRS) }\end{array}$ \\
\hline $\begin{array}{l}\text { Proper timing of } \\
\text { implantation }\end{array}$ & $\begin{array}{l}\text { ICD should be implanted in } \\
\text { primary prevention only after at } \\
\text { least } 3 \text { months of OMT }\end{array}$ & $\begin{array}{l}\text { Identification of higher-risk patients } \\
\text { who could benefit from early ICD } \\
\text { implantation (higher LVESVi; larger } \\
\text { QRS; intolerance to beta-blockers) } \\
\text { Defining a role for wearable } \\
\text { cardioverter-defibrillators }\end{array}$ \\
\hline $\begin{array}{l}\text { Periodic } \\
\text { reassessment of } \\
\text { arrhythmic risk }\end{array}$ & $\begin{array}{l}\text { Currently, no time-dependent } \\
\text { parameters are known }\end{array}$ & $\begin{array}{l}\text { Creation of a dynamic score, with } \\
\text { different predictors at subsequent } \\
\text { evaluations }\end{array}$ \\
\hline
\end{tabular}

$D C M$ dilated cardiomyopathy, FLNC filamin, $G L S$ global longitudinal strain, $I C D$ implantable cardioverter-defibrillator, $L A E F$ left atrial emptying fraction, $L G E$ late gadolinium enhancement, $L M N A$ lamin, $L V E F$ left ventricular ejection fraction, $L V E S V i$ left ventricular end-systolic volume indexed, NYHA New York Heart Association, NSVT nonsustained ventricular tachycardia, OMT optimized medical therapy 


\section{References}

1. Elliott P, Andersson B, Arbustini E, Bilinska Z, Cecchi F, Charron P, et al. Classification of the cardiomyopathies: a position statement from the European Society of Cardiology Working Group on Myocardial and Pericardial Diseases. Eur Heart J. 2008;29:270-6.

2. Merlo M, Anzini M, Bussani R, Artico J, Barbati G, Stolfo D, et al. Characterization and longterm prognosis of postmyocarditic dilated cardiomyopathy compared with idiopathic dilated cardiomyopathy. Am J Cardiol. 2016;118:895-900.

3. Brembilla-Perrot B, Ferreira JP, Manenti V, Sellal JM, Olivier A, Villemin T, et al. Predictors and prognostic significance of tachycardiomyopathy: insights from a cohort of 1269 patients undergoing atrial flutter ablation. Eur J Heart Fail. 2016;18:394-401.

4. Cooper LT, Mather PJ, Alexis JD, Pauly DF, Torre-Amione G, Wittstein IS, et al. Myocardial recovery in peripartum cardiomyopathy: prospective comparison with recent onset cardiomyopathy in men and nonperipartum women. J Card Fail. 2012;18:28-33.

5. Guzzo-Merello G, Segovia J, Dominguez F, Cobo-Marcos M, Gomez-Bueno M, Avellana P, et al. Natural history and prognostic factors in alcoholic cardiomyopathy. JACC Heart Fail. 2015;3:78-86.

6. Arbustini E, Narula N, Tavazzi L, Serio A, Grasso M, Favalli V, et al. The MOGE(S) classification of cardiomyopathy for clinicians. J Am Coll Cardiol. 2014;64:304-18.

7. Moretti M, Merlo M, Barbati G, Di Lenarda A, Brun F, Pinamonti B, et al. Prognostic impact of familial screening in dilated cardiomyopathy. Eur J Heart Fail. 2010;12:922-7.

8. Fatkin D, Yeoh T, Hayward CS, Benson V, Sheu A, Richmond Z, et al. Evaluation of left ventricular enlargement as a marker of early disease in familial dilated cardiomyopathy. Circ Cardiovasc Genet. 2011;4:342-8.

9. Lakdawala NK, Thune JJ, Colan SD, Cirino AL, Farrohi F, Rivero J, et al. Subtle abnormalities in contractile function are an early manifestation of sarcomere mutations in dilated cardiomyopathy. Circ Cardiovasc Genet. 2012;5:503-10.

10. Priori SG, Blomström-Lundqvist C, Mazzanti A. 2015 ESC guidelines for the management of patients with ventricular arrhythmias and the prevention of sudden cardiac death. Eur Heart J. 2015;8:746-837.

11. Merlo M, Sinagra G, Carniel E, Slavov D, Zhu X, Barbati G, et al. Poor prognosis of rare sarcomeric gene variants in patients with dilated cardiomyopathy. Clin Transl Sci. 2013;6:424-8.

12. Dal Ferro M, Stolfo D, Altinier A, Gigli M, Perrieri M, Ramani F, et al. Association between mutation status and left ventricular reverse remodelling in dilated cardiomyopathy. Heart. 2017;103:1704-10.

13. Jacoby D, McKenna WJ. Genetics of inherited cardiomyopathy. Eur Heart J. 2012;33:296-304.

14. Begay RL, Graw S, Sinagra G, Merlo M, Slavov D, Gowan K, et al. Role of titin missense variants in dilated cardiomyopathy. J Am Heart Assoc. 2015;4(11).

15. Ware JS, Li J, Mazaika E, Yasso CM, DeSouza T, Cappola TP, et al. Shared genetic predisposition in peripartum and dilated cardiomyopathies. N Engl J Med. 2016;374:233-41.

16. Ware JS, Amor-Salamanca A, Tayal U, Govind R, Serrano I, Pascual-figal DA, et al. Genetic etiology for alcohol-induced cardiac toxicity. J Am Coll Cardiol. 2018;71:2293-302.

17. Hazebroek MR, Moors S, Dennert R, van den Wijngaard A, Krapels I, Hoos M, et al. Prognostic relevance of gene-environment interactions in patients with dilated cardiomyopathy: applying the MOGE(S) classification. J Am Coll Cardiol. 2015;66:1313-23.

18. Sen-Chowdhry S, Syrris P, Pantazis A, Quarta G, McKenna WJ, Chambers JC. Mutational heterogeneity, modifier genes, and environmental influences contribute to phenotypic diversity of arrhythmogenic cardiomyopathy. Circ Cardiovasc Genet. 2010;3:323-30.

19. Hershberger RE, Hedges DJ, Morales A. Dilated cardiomyopathy: the complexity of a diverse genetic architecture. Nat Rev Cardiol. 2013;10:531-47.

20. Menon SC, Michels VV, Pellikka PA, Ballew JD, Karst ML, Herron KJ, et al. Cardiac troponin $\mathrm{T}$ mutation in familial cardiomyopathy with variable remodeling and restrictive physiology. Clin Genet. 2008;74:445-54.

21. Halliday BP, Cleland JGF, Goldberger JJ, Prasad SK. Personalizing risk stratification for sudden death in dilated cardiomyopathy. Circulation. 2017;136:215-31. 
22. Ponikowski P, Voors AA, Anker SD, Bueno H, Cleland JGF, Coats AJS, et al. 2016 ESC guidelines for the diagnosis and treatment of acute and chronic heart failure. Eur Heart $\mathrm{J}$. 2016;37:2129-2200m.

23. Bansch D. Primary prevention of sudden cardiac death in idiopathic dilated cardiomyopathy: the cardiomyopathy trial (CAT). Circulation. 2002;105:1453-8.

24. Strickberger SA, Hummel JD, Bartlett TG, Frumin HI, Schuger CD, Beau SL, et al. Amiodarone versus implantable cardioverter-defibrillator: randomized trial in patients with nonischemic dilated cardiomyopathy and asymptomatic nonsustained ventricular tachycardia-AMIOVIRT. J Am Coll Cardiol. 2003;41:1707-12.

25. Kadish A, Dyer A, Daubert JP, Quigg R, Estes NAM, Anderson KP, et al. Prophylactic defibrillator implantation in patients with nonischemic dilated cardiomyopathy for the defibrillators in non-ischemic cardiomyopathy treatment evaluation (DEFINITE) investigators. N Engl J Med. 2004;350:2151-8.

26. Bardy GH, Lee KL, Mark DB, Poole JE, Packer DL, Boineau R, et al. Amiodarone or an implantable cardioverter-defibrillator for congestive heart failure. N Engl J Med. 2005;352:225-37.

27. Køber L, Thune JJ, Nielsen JC, Haarbo J, Videbæk L, Korup E, et al. Defibrillator implantation in patients with nonischemic systolic heart failure. N Engl J Med. 2016;375:1221-30.

28. Al-Khatib SM, Hellkamp A, Curtis J, Mark D, Peterson E, Sanders GD, et al. Non-evidencebased ICD implantations in the United States. JAMA. 2011;305:43-9.

29. Mozaffarian D, Anker SD, Anand I, Linker DT, Sullivan MD, Cleland JGF, et al. Prediction of mode of death in heart failure: the Seattle heart failure model. Circulation. 2007;116:392-8.

30. Zhang Y, Guallar E, Blasco-Colmenares E, Dalal D, Butcher B, Norgard S, et al. Clinical and serum-based markers are associated with death within 1 year of de novo implant in primary prevention ICD recipients. Heart Rhythm. 2015;12:360-6.

31. Spezzacatene A, Sinagra G, Merlo M, Barbati G, Graw SL, Brun F, et al. Arrhythmogenic phenotype in dilated cardiomyopathy: natural history and predictors of life-threatening arrhythmias. J Am Heart Assoc. 2015;4:e002149.

32. Begay RL, Graw SL, Sinagra G, Asimaki A, Rowland TJ, Slavov DB, et al. Filamin C truncation mutations are associated with arrhythmogenic dilated cardiomyopathy and changes in the cell-cell adhesion structures. JACC Clin Electrophysiol. 2018;4:504-14.

33. Fiset C, Giles WR. Cardiac troponin T mutations promote life-threatening arrhythmias. J Clin Invest. 2008;118:3845-7.

34. Van Rijsingen IAW, Van Der Zwaag PA, Groeneweg JA, Nannenberg EA, Jongbloed JDH, Zwinderman AH, et al. Outcome in phospholamban R14del carriers results of a large multicentre cohort study. Circ Cardiovasc Genet. 2014;7:455-65.

35. Refaat MM, Lubitz SA, Makino S, Islam Z, Frangiskakis JM, Mehdi H, et al. Genetic variation in the alternative splicing regulator RBM20 is associated with dilated cardiomyopathy. Heart Rhythm. 2012;9:390-6.

36. Verdonschot JAJ, Hazebroek MR, Derks KWJ, Barandiarán Aizpurua A, Merken JJ, Wang P, et al. Titin cardiomyopathy leads to altered mitochondrial energetics, increased fibrosis and long-term life-threatening arrhythmias. Eur Heart J. 2018;39:864-73.

37. Haugaa KH, Goebel B, Dahlslett T, Meyer K, Jung C, Lauten A, et al. Risk assessment of ventricular arrhythmias in patients with nonischemic dilated cardiomyopathy by strain echocardiography. J Am Soc Echocardiogr. 2012;25:667-73.

38. Gulati A, Jabbour A, Ismail TF, Guha K, Khwaja J, Raza S, et al. Association of fibrosis with mortality and sudden cardiac death in patients with nonischemic dilated cardiomyopathy. JAMA. 2013;309:896-908.

39. Di Marco A, Anguera I, Schmitt M, Klem I, Neilan T, White JA, et al. Late gadolinium enhancement and the risk for ventricular arrhythmias or sudden death in dilated cardiomyopathy: systematic review and meta-analysis. JACC Heart Fail. 2017;5:28-38.

40. Chen Z, Sohal M, Voigt T, Sammut E, Tobon-Gomez C, Child N, et al. Myocardial tissue characterization by cardiac magnetic resonance imaging using T1 mapping predicts ventricular arrhythmia in ischemic and non-ischemic cardiomyopathy patients with implantable cardioverter-defibrillators. Heart Rhythm. 2015;12:792-801. 
41. Gulati A, Ismail TF, Jabbour A, Alpendurada F, Guha K, Ismail NA, et al. The prevalence and prognostic significance of right ventricular systolic dysfunction in nonischemic dilated cardiomyopathy. Circulation. 2013;128:1623-33.

42. Merlo M, Gobbo M, Stolfo D, Losurdo P, Ramani F, Barbati G, et al. The prognostic impact of the evolution of RV function in idiopathic DCM. JACC Cardiovasc Imaging. 2016;9:1034-42.

43. Rijnierse MT, Kamali Sadeghian M, Schuurmans Stekhoven S, Biesbroek PS, van der Lingen ALC, van de Ven PM, et al. Usefulness of left atrial emptying fraction to predict ventricular arrhythmias in patients with implantable cardioverter defibrillators. Am J Cardiol. 2017;120:243-50.

44. Goldberger JJ, Subačius H, Patel T, Cunnane R, Kadish AH. Sudden cardiac death risk stratification in patients with nonischemic dilated cardiomyopathy. J Am Coll Cardiol. 2014;63:1879-89.

45. Zecchin M, Merlo M, Pivetta A, Barbati G, Lutman C, Gregori D, et al. How can optimization of medical treatment avoid unnecessary implantable cardioverter-defibrillator implantations in patients with idiopathic dilated cardiomyopathy presenting with "SCD-HeFT criteria?". Am J Cardiol. 2012;109:729-35.

46. Losurdo P, Stolfo D, Merlo M, Barbati G, Gobbo M, Gigli M, et al. Early arrhythmic events in idiopathic dilated cardiomyopathy. JACC Clin Electrophysiol. 2016;2:535-43.

47. Kutyifa V, Moss AJ, Klein H, Biton Y, McNitt S, MacKecknie B, et al. Use of the wearable cardioverter defibrillator in high-risk cardiac patients data from the prospective registry of patients using the wearable cardioverter defibrillator (WEARIT-II registry). Circulation. 2015;132:1613-9.

48. Stolfo D, Ceschia N, Zecchin M, De Luca A, Gobbo M, Barbati G, et al. Arrhythmic risk stratification in patients with idiopathic dilated cardiomyopathy. Am J Cardiol. 2018;121:1601-9.

49. Merlo M, Pivetta A, Pinamonti B, Stolfo D, Zecchin M, Barbati G, et al. Long-term prognostic impact of therapeutic strategies in patients with idiopathic dilated cardiomyopathy: changing mortality over the last 30 years. Eur J Heart Fail. 2014;16:317-24.

50. McMurray JJV, Packer M, Desai AS, Gong J, Lefkowitz MP, Rizkala AR, et al. Angiotensinneprilysin inhibition versus enalapril in heart failure. N Engl J Med. 2014;371:993-1004.

51. Maring JA, Beez CM, Falk V, Seifert M, Stamm C. Myocardial regeneration via progenitor cell-derived exosomes. Stem Cells Int. 2017;2017:7849851.

52. Hare JM, DiFede DL, Castellanos AM, Florea V, Landin AM, El-Khorazaty J, et al. Randomized comparison of allogeneic vs. autologous mesenchymal stem cells for non-ischemic dilated cardiomyopathy: POSEIDON-DCM trial. J Am Coll Cardiol. 2017;69:526-37.

53. Woitek F, Zentilin L, Hoffman NE, Powers JC, Ottiger I, Parikh S, et al. Intracoronary cytoprotective gene therapy: a study of VEGF-B167 in a pre-clinical animal model of dilated cardiomyopathy. J Am Coll Cardiol. 2015;66:139-53.

54. Giacca M, Zacchigna S. Harnessing the microRNA pathway for cardiac regeneration. J Mol Cell Cardiol. 2015;89(Pt A):68-74.

Open Access This chapter is licensed under the terms of the Creative Commons Attribution 4.0 International License (http://creativecommons.org/licenses/by/4.0/), which permits use, sharing, adaptation, distribution and reproduction in any medium or format, as long as you give appropriate credit to the original author(s) and the source, provide a link to the Creative Commons license and indicate if changes were made.

The images or other third party material in this chapter are included in the chapter's Creative Commons license, unless indicated otherwise in a credit line to the material. If material is not included in the chapter's Creative Commons license and your intended use is not permitted by statutory regulation or exceeds the permitted use, you will need to obtain permission directly from the copyright holder.

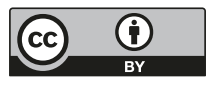

